\title{
Os lugares da cidade em Hotel Siesta e o Trânsito Metafórico de Feliciano De Mira
}

\author{
Wellington Amâncio Da Silva*
}

\begin{abstract}
Resumo
Este ensaio objetiva descrever e analisar o conteúdo documental, artístico e literário do livro Hotel Siesta, de Feliciano de Mira. Esta obra tem uma cronologia e uma espacialidade próprias, aludindo às viagens intercontinentais e experiências da cidade, sem formalmente possuir o caráter de "diário de viagem", porque as narrativas ornam-se de excursões oníricas, poéticas, imagéticas, mnemônicas e pictóricas, diante da presença das cidades, na qualidade de lugar de certas especificidades objetivas e subjetivas - para não falar nas diversas outras concretizações estilísticas, fruto do entrecruzamento constante das demais categorias literárias, narrativas, epistolares e locacionais. Para o jogo livre da presente narrativa-análise, utilizamos da metodologia desenvolvida por Feliciano de Mira, a Epistemologia Metafórica.
\end{abstract}

Palavras-chave: Poesia Concreta. Representação da Cidade. Literatura Portuguesa. Hotel Siesta. Feliciano de Mira.

\section{The Places of City in Hotel Siesta, and Metaphorical Transit from Feliciano De Mira}

\begin{abstract}
This essay aims to describe and to analyze the documentary, artistic and literary content of the book Hotel Siesta, by Feliciano de Mira. This work has a chronology and its own spatiality, alluding to the intercontinental travel, and cities-experiences without a format of the "travel diary", because the narratives are made up of dreaming, poetic, imaginary, mnemonic and pictorial excursions, in front of the cities' presence, as a place of certain objective and subjective specificities - and even the various other stylistic concretions from a constant intersection with the literary, narrative and epistolary categories. For the free play narrative-analysis, we used the methodology developed by Feliciano de Mira, called Metaphorical Epistemology.
\end{abstract}

Keywords: Concrete Poetry. City Representatio. Portuguese Literature. Hotel Siesta. Feliciano de Mira.

Recebido: 06/03/2018

Aceito: 10/12/2018

\footnotetext{
* Universidade Federal de Alagoas - UFAL, Campus Sertão. Mestre em Ecologia Humana pelo Programa de PósGraduação em Ecologia Humana no Campus VIII da Universidade Estadual da Bahia (UNEB). É membro dos Grupos de Pesquisa, "Ecologia Humana" (SABEH/CNPq) e "Socioeconomia do Desenvolvimento Sustentável" (UNEB/CNPq).
} 


\section{Introdução}

Quando senti que a desconstrução global começava a tomar conta do mundo, abri a palma da minha mão esquerda e vi sair o reflexo incandescente das pedras vulcânicas de El Salvador, Centro América. Feliciano de Mira

Feliciano de Mira ${ }^{1}$ nasceu em Arroiolos, Portugal, em 1957. Esteve singrando os mares e pairando os ares em direção a quatro continentes, a Europa, a África, a América Latina e a América do Norte. Atualmente, além do Brasil, tem residido em vários países. Feliciano de Mira publicou o Hotel Siesta em 2017, pela Editora Palimage Coimbra 2017. Escreveu-o durante os vários anos de viagem. O livro possui 122 páginas e mais de 100 figuras entre montagens fotográficas e poemas concretos. Esta obra contém uma séria de desenhos, isto é, poesias concretas experimentais de grande originalidade: pela reorganização lógico-sensível da afiguração concreta antes esboçada na fonte de espontaneidade, seu lugar de intuição. Sem quaisquer pretensões simplificadoras da realidade, o autor intercala, amálgama e faz transitar, pela força da arte — arrolada de sua subjetividade — diversos níveis de representação da realidade. Hotel Siesta é antes de tudo um diário de viagem, em sua maioria, viagens de facto, muito embora ornamentadas por viagens oníricas, poéticas, imagéticas, mnemônicas e pictóricas, contadas em fluxos de pensamento e de memória - para não falar nas diversas outras concretizações estilísticas fruto do entrecruzamento constante das demais categorias literárias, narrativas e epistolares, no âmbito de uma liberdade de construção estilística própria de uma mente que "contorna para além" as muitas concepções modernas de fronteiras e limítrofes conceituais, estéticos e paradigmáticos. Em sua obra, especificamente nesta, é bem possível entrever aquele universo literário típico da Noigrandes (1952-1962).

\section{As cidade em Hotel Siesta e seus imbricamentos no ser do autor}

Surpreende-nos que nas primeiras páginas, por meio de uma narrativa de "diário de viagens", há um forte trânsito metafórico presente nas sentenças (do relato dos fatos entremeado de figuras poéticas), misto de viés "impressionista", na forma de representar os acontecimentos, e de uma visão de mundo quase onírica, uma ponderação quase surrealista diante dos acontecimentos vivenciados, mas que não se perdem em meio à narrativa precisamente realista quando suscita os acontecimentos que vivenciou. As representações, em sua narrativa sobre os factos - e os "factos" não prescindem da experiência subjetiva do narrador diante da história vivida - são apresentadas de modo muito pessoal em que cada detalhe descrito expressam a ligação afetiva, artística e mnemônica do autor aos elementos constitutivos da realidade relembrada - e este trânsito de metáforas, dentro da realidade relatada, ocorre na simples junção da escrita de repostagem com a escrita literária. Se Hayden White (1995) afirmava que os discursos históricos são tais como tropos, aqui, Mira aplica uns tropos no objetivo de deixar a história contada transcender aquele modelo formal de representação de um facto, dando espaço à metáfora; sua imaginação histórica e pós-moderna a todo tempo parece reger esta difícil sinfonia entre o relato instrumental histórico e sua partitura metafórica ${ }^{2}$ na condição de horizonte onde os factos vividos são

\footnotetext{
1 Doutor em Socio-économie du Développement pela École des Hautes Études en Sciences Sociales de Paris. É doutor em Sociologia Econômica e das Organizações, pelo Instituto Superior de Economia e Gestão da Universidade Técnica de Lisboa. Pós-Doutor em Estudos Culturais Comparados no Centro de Estudos Sociais da Universidade de Coimbra.

2 Em “Ao correr do Olhar" (2013) o autor parece adorar o mesmo princípio de aplicar a metáfora como uma linha colorida na tessitura de cores formais da metodologia de pesquisa das conceituações correlatas. É preciso reconhecer neste livro uma consistente realização de um livro de metodologia de pesquisa, relatos de pesquisa dentro de um transito metafórico que preenche as tradicionais lacunas deixada pela ânsia de objetividade; os aspectos subjetivos da Metáfora exortam a todo tempo para o fato de que é preciso reconhecer o caudal de subjetividades humanas que escapa pelas bordas do
} 
apresentados.

O livro é divido em onze partes enumeradas em algarismos romanos, quais sejam: "Hotel Siesta"; "Entre o Retrato e o Espelho"; “Angústia”; "O pião"; "Évora”; "Capelas Imperfeitas”; "O Rapaz do Teatro Nacional"; "Fractura"; "O Carocha"; "A Menina"; "Rosa dos Ventos". A temporalidade da produção nasce mais ou menos na década de 70 até o momento presente, demonstrando profunda coerência acerca da linguagem e signos adotados, bem como da estruturação do discurso poéticopolítico afirmado. No capítulo "Hotel Siesta", temos uma narrativa cujas reflexões muito pessoais e na maioria das vezes refletidas a partir de outro lugar — tratam de acontecimentos em Moçambique, Angola, Etiópia, Portugal, especialmente sobre a instabilidade política em El Salvador ("Um grupo de guerrilheiros aproveitou a siesta dos vulcões"). Inspirado em uma conversa com Eduardo Galeano (“As veias abertas da América Latina"), em pleno voo a Miami, Feliciano confessa o quão maravilhoso é "ouvir os livros a falarem, com a cabeça mais próxima do céu e da lua sem os pés estarem assentes na terra, mantendo-me concretista e progenitor de verdades poéticas de outra-tradição". Este é o nível pessoal e metafórico da obra em questão. Um dos fatos principais diz respeito à situação do autor em ser obrigado a estar "num lugar limítrofe entre nações", instalado no Miami International Airport, situado no Terminal Concourse-E, e a sua luta em "procurar formas de desafiar a espera deste não-lugar". No centro da narrativa há uma exposição imparcial sobre a dicotomia das vidas sob o Capitalismo e sob o Socialismo (Cuba) a partir da consideração aos relatos destes sujeitos diaspóricos (Eduardo Galeano; o barbeiro cubano; as mulheres e homens em protesto em San Benito, El Salvador).

"Entre o Retrato e o Espelho" é composto de 11 poemas visuais, predominantemente em noir et blanc. Nos dois primeiros poemas há a fotografia "tratada" do autor na condição de elemento composicional que lembra tanto um espelho quebrado como a sobreposição especular de uma mesma figura; aquela figura é vista, por assim dizer, num rio translúcido, cujo protagonista se enxerga como um anti-narciso, qual seja, mais interessado na imagem de si, no horizonte metafórico da poesia visual praticada, na qualidade de um homo-poeticus, do que da sua representação vazia, figurativa, apenas. $\mathrm{O}$ aparente hiato, entre o "retrato e o espelho" é uma epoché, isto é, uma suspensão de qualquer pretensão de dizer quem é enquanto sujeito, visto que ali "vida e obra" ultrapassam qualquer isonomia, ou "acordo", na verdade são como "um". Devido à complexidade ontológica e existencial do autor, dizer de si e dizer-se requerem um hibridismo de elementos composicionais, na extensão plausível da obra de arte (até onde permite-se entendê-la, dentro da sua orla de sentido, da sua forma quadrada de ser e de enquadrar uma enunciação artístico-poética), que faz corar as convenções do tradicional estético. Quando se diz: "Depois do espelho partido passei a escrever sobre o pentágono o que escrevera no quadro negro do tempo do bibe de quadriculado azul, quando o branco do giz exalava a grande luz de outros meridianos". Se o quadro negro do tempo do bibe remete à infância, na escola do aprender fechado, já estruturado para formar o ser, o branco do giz, aberto, sobreposição das experiências de vida, registra, pelo crivo do próprio autor, suas impressões de viagens por Moçambique, Europa e América Latina. Esses percursos de além-mar é são antes definidos por seus motivos iniciais, isto é, quando se diz, "Depois do espelho partido e o retrato rasgado, reparti a alma pelos céus do mundo, lendo de prumo a celebração da terra mesmo com a alma estilhaçada", percebemos a consolidação destas experiências de viagens por outros meridianos sem a perda de lucidez poética do autor que mesmo desconstruindo os velhos dispositivos de representação de si (espelho partido e o retrato rasgado) vai buscar em lugares outros a sua própria imagem, bem como os sentidos novos que ela representa a partir das novas alteridades de além-mar, em fragmentos especulares necessários. A inteireza do antigo espelho e a hiperrealidade da fotografia não foram suficientes para abarcar a multiplicidade do ser do autor - fora preciso parti-lo e rasgá-la, permitindo ao semblante en blanc refazer-se para si, em identidade poética da dupla imagem abaixo (MIRA, 2017, p. 28).

discurso formal. 

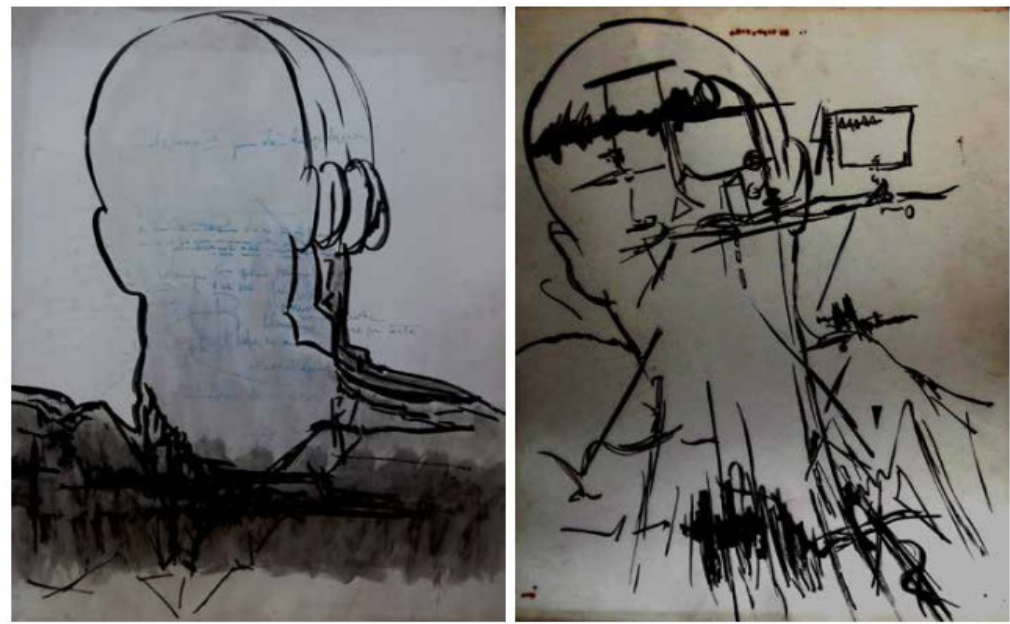

Fonte: MIRA, Feliciano, 2017.

Quando se diz, "quando voltei à caligrafia original (ao vernáculo da sua natividade, a palavra que o originou) escrevi palavras sobre palavras, retirando do cesto celeste novas ameixas tintas e caligrafias cruzadas de ortogramas das cinco partidas do mundo" isto quer dizer que o humano cosmopolitano havia nascido, e à continuidade desse projeto de humanidade requerer-se-ia a imersão gramatical e vocabular para além da língua portuguesa, bem como para além da própria linguagem formal escrita; era preciso recompor formas novas de dizer-se, arquitetar combinações em busca de um horizonte próprio, por exemplo, de uma "epistemologia metafórica" (MIRA, 2013). Por isso, para não dizer pela incompletude das enunciações formais do vernáculo, o autor desconstruindo-o remonta-o de modo singular, ao seu critério e gosto, em letras, palavras, garatujas, riscos, pontos, repetições, em forma e movimento, numa colagem de elementos cujos sedimentos de significados lembram a alma complexa do autor - facile intelligere animae ratio est.

No poema visual duplo "espelho", (imagens abaixo) é possível identificar uma estrutura sintética de um corpo cuja silhueta é toda comporta a partir da possibilidade da escrita da palavra "espelho"; e esta possibilidade exaustiva do "espelho", sempre num fundo noir, faz refletir por diversos ângulos especulares a colocação da palavra ante o olhar do espectador, que descobre atônito, algo de si, no "se" (possibilidade) e no "si" (autorreferencialidade) do autor, que perpassam estes dois poemas visuais:
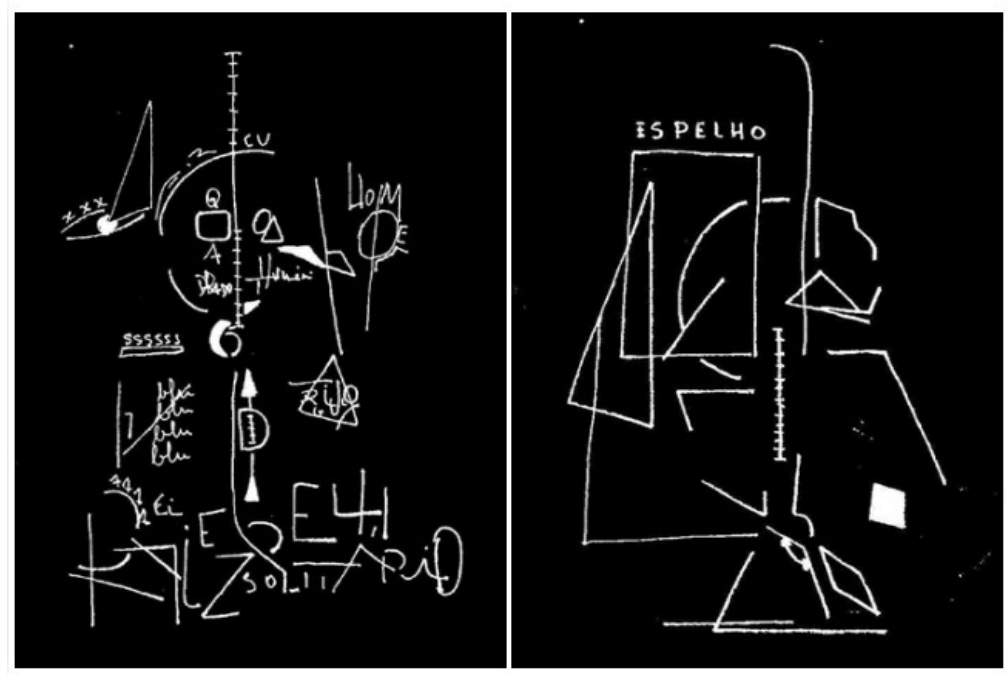

Fonte: MIRA, Feliciano, 2017. 
Em "Angústia", vemos doze poemas visuais, em crescente exercício ao propósito daquilo que sugere o título do capítulo. Antes, há um lembrete existencial para todos aqueles que objetivam o duríssimo ofício da escrita: "existem pessoas sem rosto que procuram os cafés para se sentar e escrever a lápis poemas até os bicos dos lápis se partirem” (MIRA, 2017, p. 27). O exercício angustioso desta escrita é um olhar-para-trás, "até que o carvão do bico do lápis reduz à insustentabilidade o exercício de dissolver essas ideias.” Este lembrete é anunciado por duas vezes seguidas, não apenas para reforçar duplamente a premência desta revelação, porque esta revelação mesma - de quem apreende, no caos dos cafés, um acontecimento que se repete -, só pode ser entregue se carregada da compulsividade própria do acontecimento ali relatado: o bico do lápis que se quebra à exaustão sob o peso da angústia da escrita do passado. E é nessa escrita decalcada duas vezes, como uma espécie de releitura minimalista e precisa, que se pode sentir, no recurso linguístico da repetição, na figura retórica de duplicação, a compulsão de quem escreve como o "olhar para trás". Este percurso é tratado por meio de poemas visuais, em sequências precisas (MIRA, 2017, p.29), que tratam desta dimensão psicológica da angústia, no seu nascedouro - memórias, escrita e bicos de lápis quebrados - a sua repercussão; na imagem abaixo (MIRA, 2017, p. 28), “existem pessoas sem rosto que procuram os cafés para se sentar e escrever a lápis poemas de dor, até os bicos dos lápis se partirem por completo ${ }^{3 "}$ ".

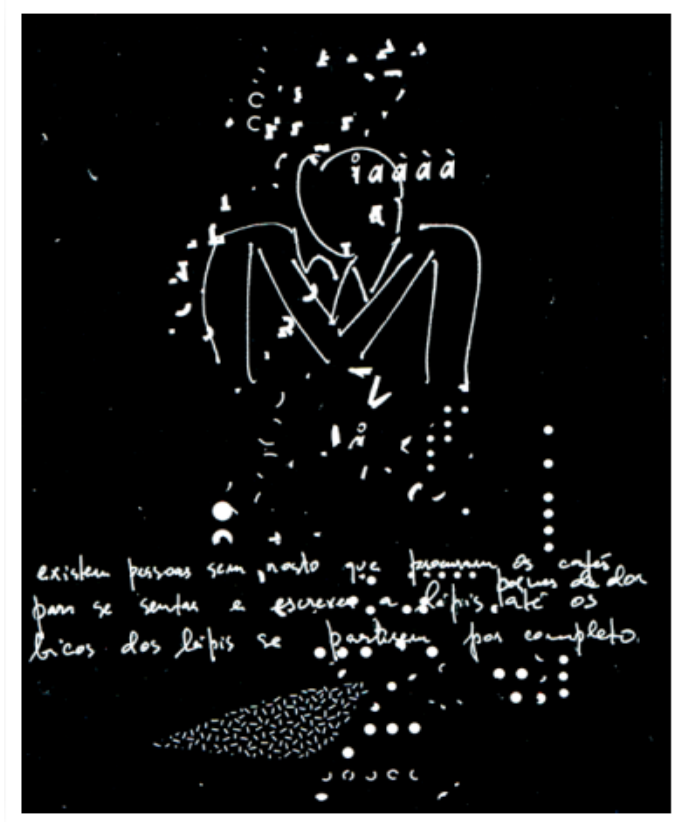

Fonte: MIRA, Feliciano, 2017.

$\mathrm{Na}$ imagem (acima) há esboçada uma figura angustiada, de terno e gravata, circundada de propagações alfabéticas, que pairam sobre sua cabeça, fazendo espirais e círculos; que rodeiam todo o seu corpo - isso faz alusão ao poder da linguagem sobre o ser do anthropos mnémonikós ${ }^{4}$. Aos pés deste, como um tapete perspectivado, as letras, outrora precisas, caem sobre um chão impreciso e se dissolvem em nada (nem ao menos em garatujas acabam); na perspectiva do tapete sugere-se que estas "letras dissolvidas", como a memória das pessoas, vão sendo deixadas no caminho - que caminho? E ainda há demasiadas reticências.

3 A palavra "completo" não existe no corpo do texto original. Somente no poema visual. Isso porque, com este poema o exercício se completa, o processo do texto inicial à imagem figurada no poema se completa. Este poema visual é o ponto final à prefaciação da página 27.

4 Ser humano dotado de memória e linguagem, considerando as interações entre estas duas como condição e possibilidade ontológicas de ser. No entanto, angustiosamente o anthropos mnémonikós necessita da escrita (linguagem como estabelecimento de sentidos sobre uma superfície neutra, branca, o papel) para ressuscitar seus fantasmas quarados na extensividade diacrônica do tempo. 

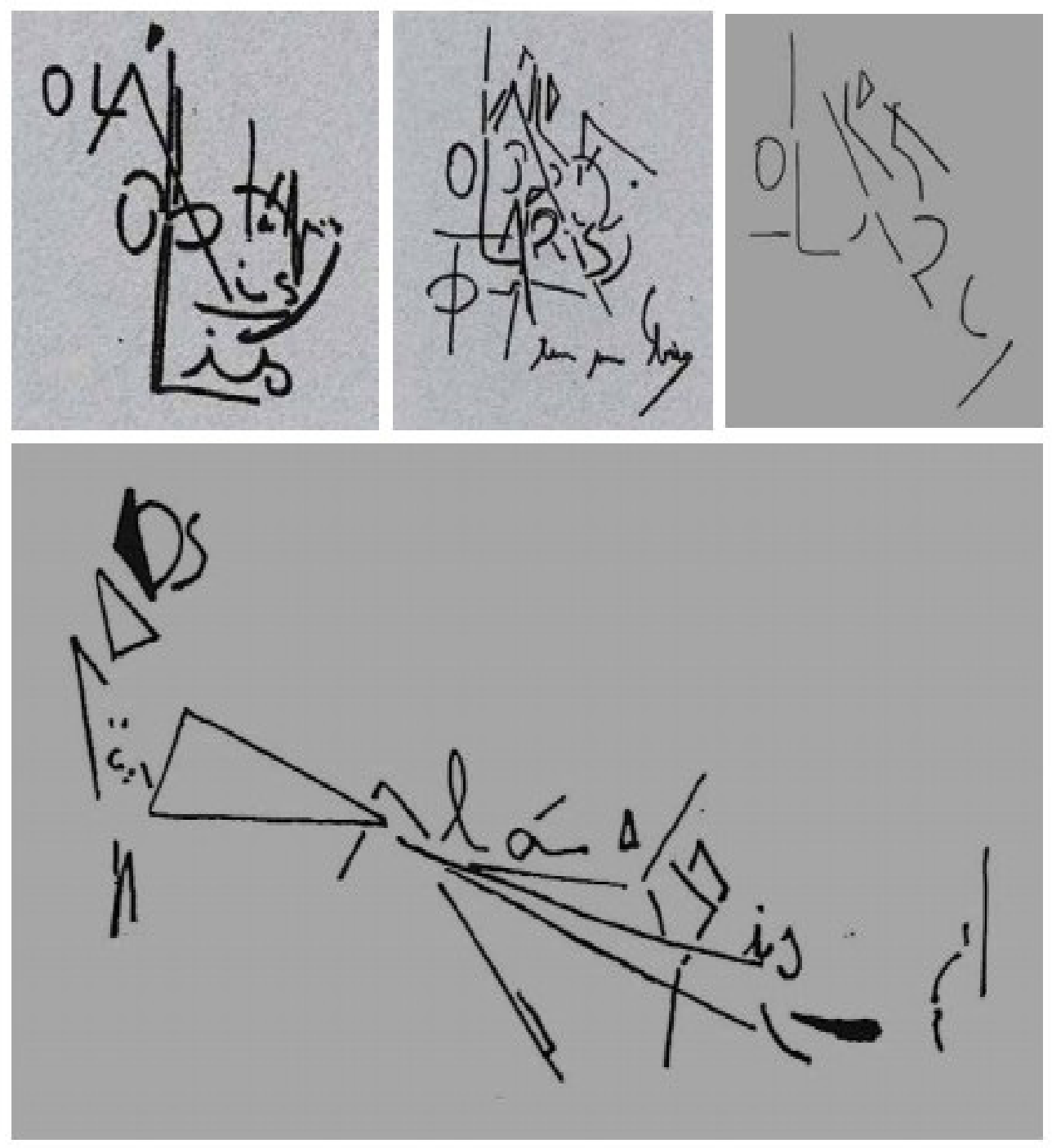

Fonte: MIRA, Feliciano, 2017.

No poema “O(s) Lápis” (MIRA, 2017, p.30) - composto de um tríptico e de um desenho maior, síntese dos três primeiros - o autor desconstrói as possibilidades da forma-lápis, ao tempo em que faz interagir sua forma com as letras que desenha no papel (desejo maior), o que é uma inversão de unção. O lápis quebrado, da última imagem é o reforço compositivo do seu substantivo simples, escrito: "lápis" - sobre o desenho deste, em isonomia de significação; faz desta ferramenta algo mais que um instrumento da técnica para a qual fora criado: inversão de função, e por isso, metaescrita. Lápis: não apenas uma extensão dos dedos que desenha; suscita o arquétipo do instrumento que risca e desenha, uma extensão da voz do espírito humano; faz transitar neste espírito de escritor não apenas letras e traços que evocam o lápis, mas uma outra função: a de quebrar-se sobre o papel como um sinal preciso da angústia desse escritor que insiste em "olhar para trás". O lápis, esse instrumento a mão, deixa de ser impessoal e descartável; torna-se intrínseco ao projeto, à arte, ao autor.

Em “O pião" temos doze poemas visuais e um poema concreto, cuja distribuição de palavras e frases compõe um pião. Este aponta para a tradição portuguesa de "embarcar e navegar oceanos". O pião é a figura metafórica do viajor universal. O pião é um gira-mundo, persona metropolitana, universo em que o poeta encontra sua onde o poeta encontra a sua bússola, continuamente no provisório da estadia, quando parte da sua terra natal para um mundo outro, do devir, assentando os pés sobre os "continentes de pausa" (MIRA, 2017, p. 37). Mas, quando a nau parte, logo suscita-se a nostalgia às lembranças das "festas dos passos, fogo, glória e cristal". Mas o projeto do navegar tem seus autos e baixos ("Inoperância e Ocultação"): 

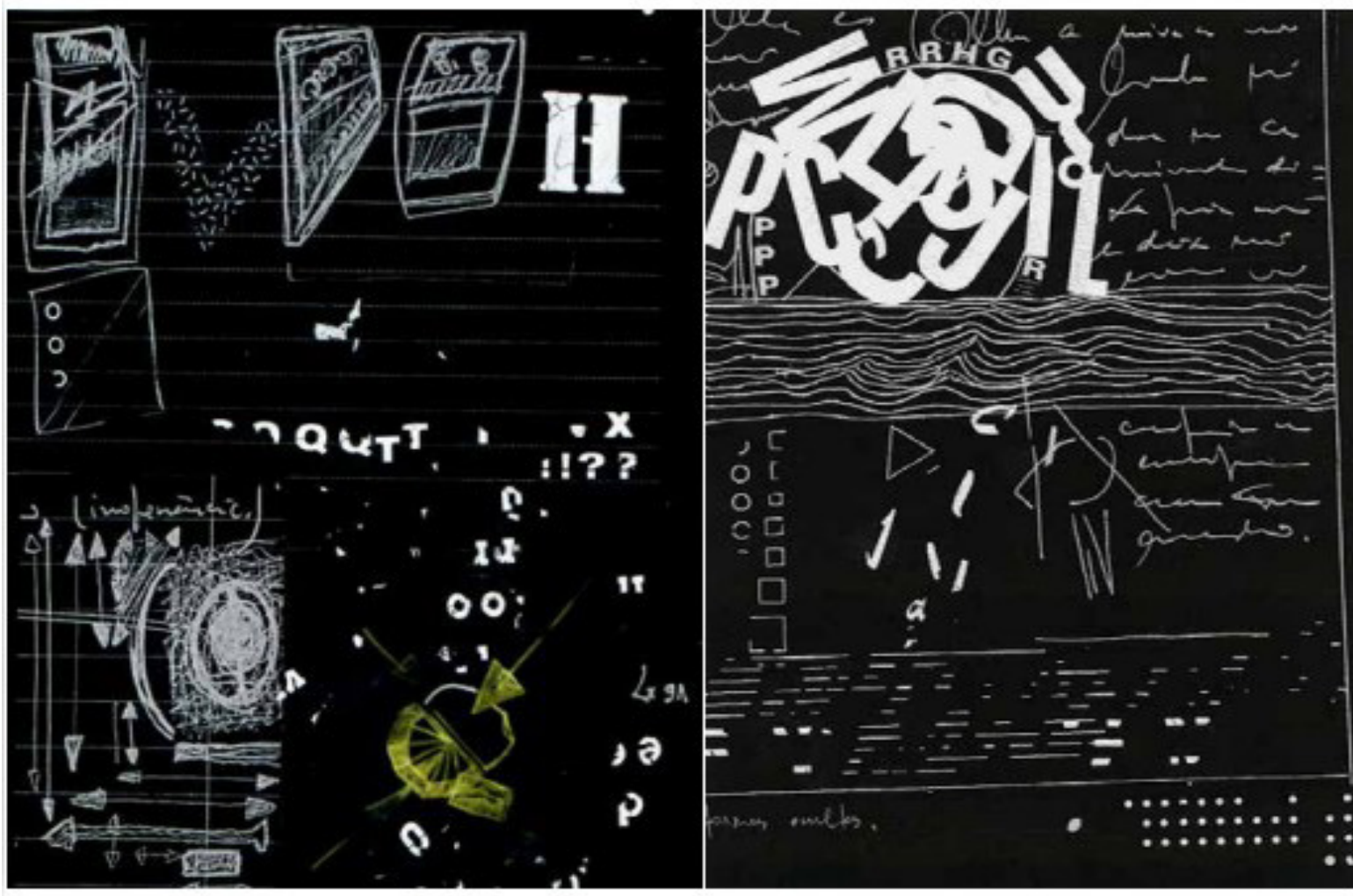

Inoperăncia e ocultação

Fonte: MIRA, Feliciano, 2017.

Na imagem acima, é possível afirmar que a essência é o projeto. Astrolábios, coordenadas, idas e vindas, setas, mantimentos ondas, vagas e um horizonte incógnito para o navegante se encontrar nas noites atlânticas; em outras palavras, este aparente emaranhado é mais que um ensaio para aquele que rearranja as letras em buscas de palavras definidoras do seu imo em alto-mar. Não há separação entre forma e conteúdo, essência e fundamento; projeto e execução dialogam aí, e ainda, causa e feito são frutos de uma isonomia pictórica, num fundo negro, cujos traços brancos reorganizam formas de coesão singulares de coesão e coerência no desenho; estes são, por si, os elementos poéticos inerentes. O capítulo denominado "Évora" é composto do texto "o quintal" e de doze poemas visuais. Eis a presença do numinoso num quintal, na cidade de Évora, tal e qual um terreiro em Salvador. Neste capítulo, há um momento de profunda epifania ao estilo de Joyce (1993) e a evocação da presença das coisas anteriores à linguagem, como em Gumbrecht (2004, 2012):

[...] Dancei de manhã comigo e com uma folha de nespereira ${ }^{5}$, esguia na forma, seca no aspecto e castanha na cor, daquelas que caíram no quintal. Foi um momento sem escrita, um processo destituído de caracteres, uma atitude obstinada de mudança (MIRA, 2017, p. 47).

Pura epifania! A dança com a folha da nespereira nas mãos, no transcurso dos afagos espirituais do autor, é mesmo o instante de revelação interior ainda que momentâneo, poderoso e marcadamente revelador. É um acontecimento ritualístico de contiguidade com a natureza e seus elementos, e ao mesmo tempo, um momento de contemplação abrupta do Inescrutável; é um transe posteriormente analisado, em que o autor busca mimetizá-lo e entendê-lo, sempre e sempre, através dos anos — com bem explica a nota de rodapé: "Selecção de anotações do ano de 1983, reescritas em 1991 em Lisboa, revistas em 1992 em Maputo e terminadas em Paris em 2002 quando regressei às Laranjas do Quintal

5 A nespereira (Eriobotrya japonica) é uma espécie vegetal da subfamília Maloideae, da família Rosaceae. Seu fruto, a nêspera, muito agridoce e mais para doce, no Brasil chama-se amexia-amarela. Todavia, como a escrita de Feliciano de Mira não é comum, é importante considerar a alusão da Nespereira que é também o nome de uma freguesia portuguesa, do antigo concelho de Guimarães, que por sua vez é cidade portuguesa próxima ao Distrito de Braga, na região do Norte e sub-região do Ave. 
entre Espelhos e Marés" (MIRA, 2017, p. 47). A "Dança Mira" “[...] foi um momento sem escrita, um processo destituído de caracteres" (p. 47), qual seja, a experiência da presença (DA SILVA, 2017), do corpo em contiguidade com a coisa-da-natureza, a "folha de nespereira" que fez despertar a percepção passageira e rara de conexão de mundo, típica dos povos étnicos, onde a atividade de busca e evocação do numinoso não era do trabalho de produção de subsistência a "sem fantasia, senão o pão real dessa manhã" (MIRA, 2017, p. 47), mas a atividade da mimese das representações espirituais presentes ali, por meio do trabalho do lúdico, do uso corpo que dança como esteio do espírito, em busca de adentramentos no horizonte das margens de sentidos, atividade de mimese para além das convenções reconhecidas. Implica no Lugar, eis a dança como reencantamento do corpo, na qualidade de imitação sutil da dinâmica do universo, e aqui, a função do corpo é a de "órgão poroso" como meio e onde transita toda a vida significada, poetizada, imaginada, "essa magia que torna as coisas simples e perdidas, ao fim do dia" (MIRA, 2017, p. 47) e a forma de cantar o acontecimento é uma espécie de epitalâmio que celebra a união entre o factual e o transcendente. Um fato clarificador do exposto é o da composição fotográfica da página 50, o "R de Reflexão (Palácio de D. Manuel, Évora,1979)", em que o autor certa vez me confidenciou: "é uma manifestação dos meus encantados". Ainda neste capítulo, o "Évora", há 16 poemas visuais de alta complexidade, e ao menos dois deles ("Évora, 1979”, e "A Fonte da Porta de Moura”, p. 52 e 53) serão tratados detidamente mais adiante. Tais poemas requerem um estudo em particular de monta, no âmbito de compreensão de uma paideuma ${ }^{6}$, e que não caberia no espaço desejado deste ensaio crítico. Em "Capelas Imperfeitas", temos o sexto capítulo laureado por um poema visual, em forma de chama de vela, e, em seu verso mais intenso o autor confessa-nos: "desejei com mais força/com a forma que revelasse o milagre" — esse "milagre" presente na concretude da forma da chama alude a uma epifania luminosa, muito longe da alusão à queima de um pavio; é muito mais do que aquilo que na linguagem insiste em dizer o que é uma chama de vela em face das suas possibilidades devocionais religiosas, talvez especificamente essa concretude da forma nos convide a pensar a Aufklärung histórica contexto no qual a poesia transita em busca de sentidos para além das formalidades de entendimento de mundo que a própria linguagem convencional cristalizou.

$\mathrm{Na}$ imagem da página 65, a silhueta antropomórfica de arame sobre um fundo de luz e sombra marrom é um exemplo dessa força que "revela o milagre" da forma como efeito, no vão não preenchido de alguma coisa, pois esta "silhueta humana" tem a função talvez apenas demarcativa sobre o quadrado não apenas como um indicativo da presença, mas alude ao autoral, à assinatura, é uma representação do próprio autor. Os exercícios caligráficos das páginas 68 a 72 — alguns redigidos em 2003 - desconstroem e reconstroem essa possibilidade autoral na assinatura como arte para além de um sinal que aponta a um autor, seu criador, mas também, como síntese de todas as assinaturas possível, no itinerário de influencias do autor. Contudo, este exercício caligráfico — por meio do assinar, do redigir pequenas sentenças — , quase inteligíveis, é mais um processo compositivo que valoriza a forma e o movimento da escrita do que a leitura formal de uma frase escrita. Os "Exercícios (Évora,1977)", da página 74, é um caso peculiar: mais um jogo geométrico com arames sobre um fundo semipintado num tecido opaco; como um todo, é uma montagem fotográfica impressa em preto e branco, cujo dedo do autor é um elemento de composição e que se relaciona contiguamente com os outros elementos compositivos da obra, fazendo alusão ao "dedo de Deus" na obra "A criação do homem", de Michelangelo7; parte do corpo do autor como elemento de composição transcende o objetivo de autoria fazendo-nos lembrar da questão da técnica e da questão da ferramenta como extensão das mãos; da técnica que se precisa e se consolida pelas mãos, e da "ferramenta-suficiente" implícita no ato em si da execução (de dobrar o arame em formas geométricas), aqui temos a "mão

6 Paideuma: a ordenação do conhecimento, de modo que o próximo homem (ou geração) possa achar, o mais rapidamente possível, a parte viva dele e gastar um mínimo de tempo com itens obsoletos. (POUND, 2006, p.161).

7 “A Criação de Adão”, de Michelangelo, é um afresco de $280 \mathrm{~cm}$ x $570 \mathrm{~cm}$, executado por volta de 1511. 
desnuda", livre de acessórios e dispositivos de execução da arte: a mão perde sua função de ferramenta técnica $(\tau \dot{\varepsilon} \chi \vee \eta)$, torna-se um objeto de arte, no conjunto da composição, e quase por um momento perde-se da sua função de "fazer coisas", tornado-se uma "coisa já-feita", ou um "objeto-preciso", juntamente com o fundo opaco e a geometria dos arames; deste modo, se temos aí uma mão que faz, temos também uma mão já feita pelo processo artístico aí presente.

Em "O Rapaz do Teatro Nacional” inicia-se a partir de um texto que, como os demais, seguem um fluxo de pensamento e da memória, prescindindo de quaisquer sinais de pontuação. Neste capítulo o autor faz alusão a fatos, sentimentos, impressões, objetos, paisagens, construções arquitetônicas e lugares em Portugal e talvez em outros países (Teatro Nacional, o capitel da coluna Dona Maria, Tejo, Bairro Alto, o mosteiro, Sam Miguel); estes elementos estão por assim dizer, interligados de modo holístico; estes se pertencem intrinsecamente no âmago do ser-metropolitano do personagem e o fundamento sobre o qual estão dispostos é o ser no que diz respeito aos seus aspectos mnemônicos e estilísticos advindos da observação das cidades. O personagem sem nome é alguém que vê e sente atônito, os factos, a vida e o lugar; na cidade onde se encontra, imanente e implicado, ele diz de si: "um fio de prumo directo ao solo e o movimento angular dos braços na continuação da passada no olhar segurava outros meridianos perseguido e possesso por aquela imagem do teatro nacional" (MIRA, 2017, p.77). A condição humana e o problema dos sentidos desta condição são duas preocupações constantes na obra do autor - e ele sabe como poucos que "a palavra correcta criou um conflito com a palavra desejada"; e esse desejo de saber, de enunciar o que é o correcto e de inclusão permanente do outro reconhece a tradição e a história da ratio ocidental, por isso mesmo em seu mundo, o mundo possível, o mundo sempre-com-o-outro, é mundo antes de tudo de emotividades cotidianas hic et nunc, porque a "emoção e razão entornar café sobre o verbo retoca a imagem das ervas a ideia do desenho o sentido marginal reparte-se o subjectivo a leveza do que se respira no ar" (MIRA, 2017, p.77). Esses elementos bucólicos — ervas, café, desenho, ar e respirar — são postos em sua obra e apresentados por novos vieses (a exemplo do café, o qual de quando em quando é um elemento pictórico utilizado em suas pinturas e desenhos), em que se busca "o sentido dos sinais contrários" (MIRA, 2017, p.78).

No capítulo "Fractura" temos de início o poema concreto, "a Ausência", escrito em 1984, na Ilha de São Miguel. Visualmente, constitui-se de sinuosidade e remete, em seu conteúdo, ao universo marítimo daquela ilha a qual celebra e evoca, em sua forma concreta, a sensualidade das ondas marinhas e entre suas letras uma poesia nostálgica: "não sei se é partir ou chegar" (MIRA, 2017, p. 85). Talvez, singrando o Atlântico, de volta à pátria, não reconheça o mesmo lugar devido ao peso das experiências de além-mar, como um Ulisses acometido de estranhamento quando do retorno ao contemplar a paisagem outra de Ítaca; esse estranhamento é como "os passos geométricos da utopia nas paredes perpendiculares do mar” (MIRA, 2017, p. 85), o horizonte já é outro. Resta-lhe o esforço por preservar o vivido, o saudoso no exercício novo desta forma de ver. Um exemplo disso consta-se em "Mar Revolto (Faial, 1984)" a tentativa possível de mimetizar aquela primeira experiência do mar que dificilmente se traduz em palavras, quaisquer que sejam estas (MIRA, 2017, p. 87). Em "Mar Revolto (Faial, 1984)" temos dois desenhos distintos; o primeiro, de fundo claro parece representar o comportamento do mar na condição de força sinuosa, em movimento, sempre; o segundo parece-nos demonstrar os modos, as manobras, as linhas de fugas e perspectivas sobre as quais os navegantes buscam situar-se: 


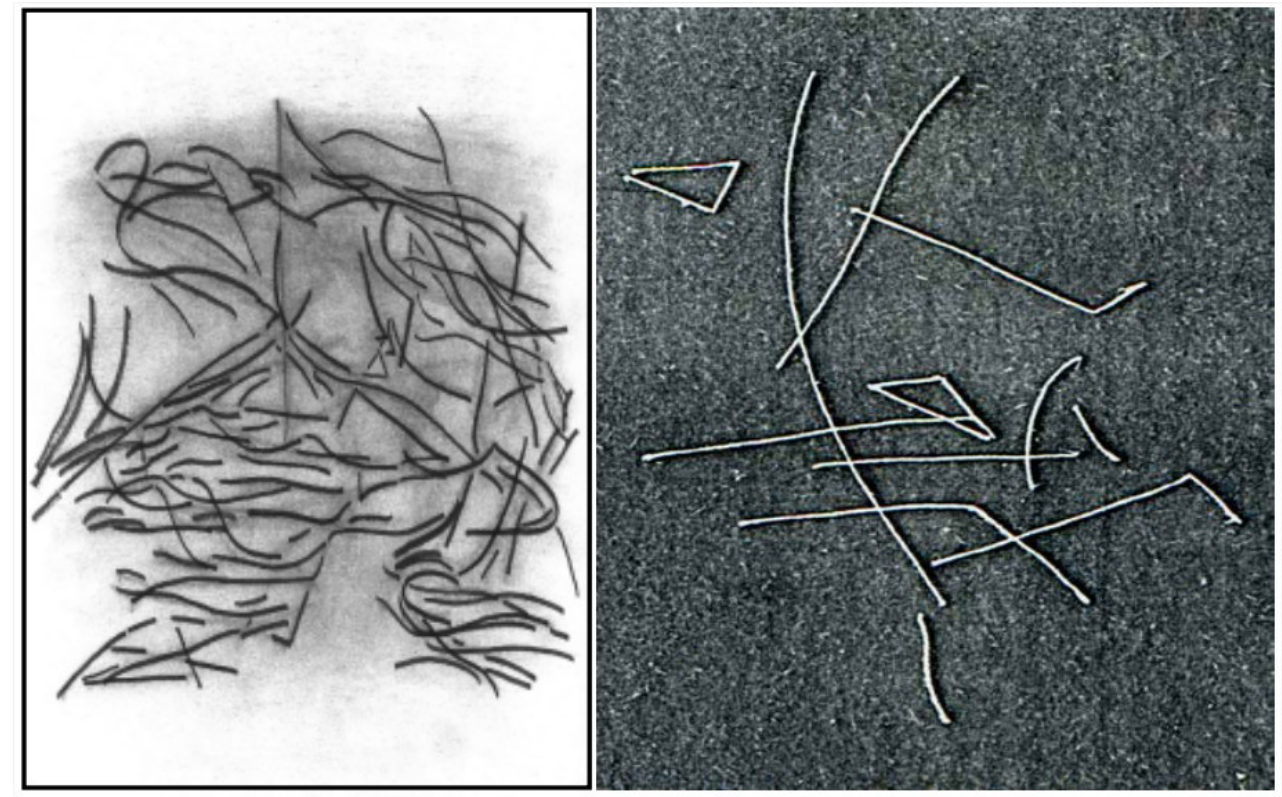

Fonte: MIRA, Feliciano, 2017.

Mas não é somente isso em "Canal do Pico" e "Mar do Açores", de 1983, registra-se o ímpeto das ondas à beira-mar. A categoria "ondulação" ou o traço que a traduz são dois aspectos essenciais, como representação ou conceito, presentes nestes poemas. A linha em contorno flexuoso, que evoca esse ondeamento, nos faz lembrar o elemento constituinte formal da escrita (cursiva, por exemplo) - a ondulação; a alusão ao mar é mais formal que abstrata no sentido de uma não-escrita alfabética, mas é toda a escrita uma denotação inevitável do mar em ondas. Assim, como uma cruz sobre um fundo branco que remete imediatamente a um hospital, as linhas sinuosas de "Mar Revolto", "Canal do Pico", "Atlântico Norte" e "Mar do Açores" denotam ao mesmo tempo escrita e vaga. Segundo o autor, "O Mar dos Açores é muito revoltoso, especialmente no Canal do Pico". O escritor português, nascido nos Açores, o grande Vitorino Nemésio trata da força da natureza em "Mau Tempo no Canal" — eis aqui uma referência adequada para entendimento dos desenhos acima expostos. Do ponto de vista do Significado, o Mar é sempre possibilidades em fim; a escrita do Mar, um recorte demasiadamente menor que os sentidos de mar (no pretérito, no presente e no devir) sobre tudo o que este pode ser, distancia-se do mar como tal. Essa busca por sentidos, num recorte, de dizê-lo o que é, é própria da poética, porque Mar é possível para nós, antes de tudo, como experiência e memória - possíveis de aludir e partilhar entre os humanos, sobretudo para aqueles que o experimentaram (mesmo os que em suas ondas se perderam). A partir de "Mar Revolto", "Canal do Pico", "Atlântico Norte" e "Mar do Açores", podemos afirmar que a arte de Feliciano de Mira se inscreve, de modo singular, na Tradição Lusitânia das narrativas a cerca do Mar (que se repete desde os povos ibéricos pré-romanos de origem indo-europeia, e na Modernidade, dos antropólogos gabaritados, Luís da Silva Fernandes e Vasco Mantas até o poeta Pessoa). Tal narrativa, de caráter fortemente metafórico, apresenta-nos a contemporização Lusitânia a partir de uma subjetividade, experimentada, reflexiva e sob um horizonte de intercontinentalidade, de intersecção das cidades vicenciadas. Disso, pensamos que a poesia visual não é apenas a busca de visualidade em uma poesia formal, mas a descoberta, por vezes experimental, de uma poesia desconhecida nas coisas, nos objetos, nas lembranças, e trazida ao centro visual desta poética, na qualidade de elementos compositivos, denotativos e conotativos neste poema desejante. A poesia visual é por natureza um espaço de trânsito da metáfora em que os elementos tipográficos no espaço desenhado se comunicam poeticamente, compondo um sentido novo.

Em "O Carocha" (alusão a um Fusca) encontramos uma empatia veicular especial — talvez a mais bela declaração de amor ao um carro já escrita -, um diálogo repleto de encontros, de compreensões, de identificações, de afetividades, de amizade e de gestos de amor, quem sabe lá de viés religioso de 
"um só corpo" e "uma só alma", etc., uma relação de "philia" com aspectos de redenção: "Saímos todos juntos, o carro, eu e duas portas. Uma abre para o céu enquanto a outra se fecha para o inferno" (MIRA, 2017, p. 94). E continua agora com a ideia de carro como ser epático: "Quando dou boleia ele fica cheio de ciúmes. Até já fomos a Arraiolos terra de judeus e ainda de bem. Ainda de bem que o meu carro não sou eu, mas eu é como se fosse ele, o cão do carro. Ele é o meu melhor amigo" (MIRA, 2017, p. 94). E aqui, um tipo de carro-semiótica sem precedentes: "Com ele saboreio o amor e trocamos conselhos com os espelhos retrovisores que olham para trás e nos avisam do futuro" (MIRA, 2017, p. 94). Segundo o autor, "o carocha era uma fusca que na década de 60 me ensinou a dirigir. Dentro do qual tive imensos momentos de amor, sexo e loucura. Foi nesse carro que também fiz muitas viagens.". Nesse sentido o autor conceitua "emoção": "É a glória e a desgraça diluídas em condimentos exactos" (MIRA, 2017, p. 94).

No capítulo “A Menina” (MIRA, 2017, p. 98-106), temos uma série de seis trabalhos entre poemas visuais, fotografia e um poema-objeto que abordam em profusão temáticas e motivos presentes na obra poética do autor. "A menina ainda não sabia falar. No aeroporto olhou pra mim” (MIRA, 2017, p. 98) nos parece a senha para o entendimento dessa epifania dupla da presença da menina que objetiva apreender o mundo dos transeuntes no olhar e do autor que se vê como ente percebido no olhar da menina (possivelmente sua filha ${ }^{8}$ ) e por isso mesmo (talvez com relação à memória da sua infância) reconhece ali uma epifania. O autor tenta explorar este singelo acontecimento a partir do estudo da forma nos poemas visuais "Segundo Exercício sobre os Pirilampos" e "A Menina e o Alfabecto (Maputo,1999)", mas, é sobretudo neste último poema em que se pode perceber o desejo de evocar de memória a forma intuída e sentida da menina que o observara. Forma consolidada em metáfora visual, sobretudo:

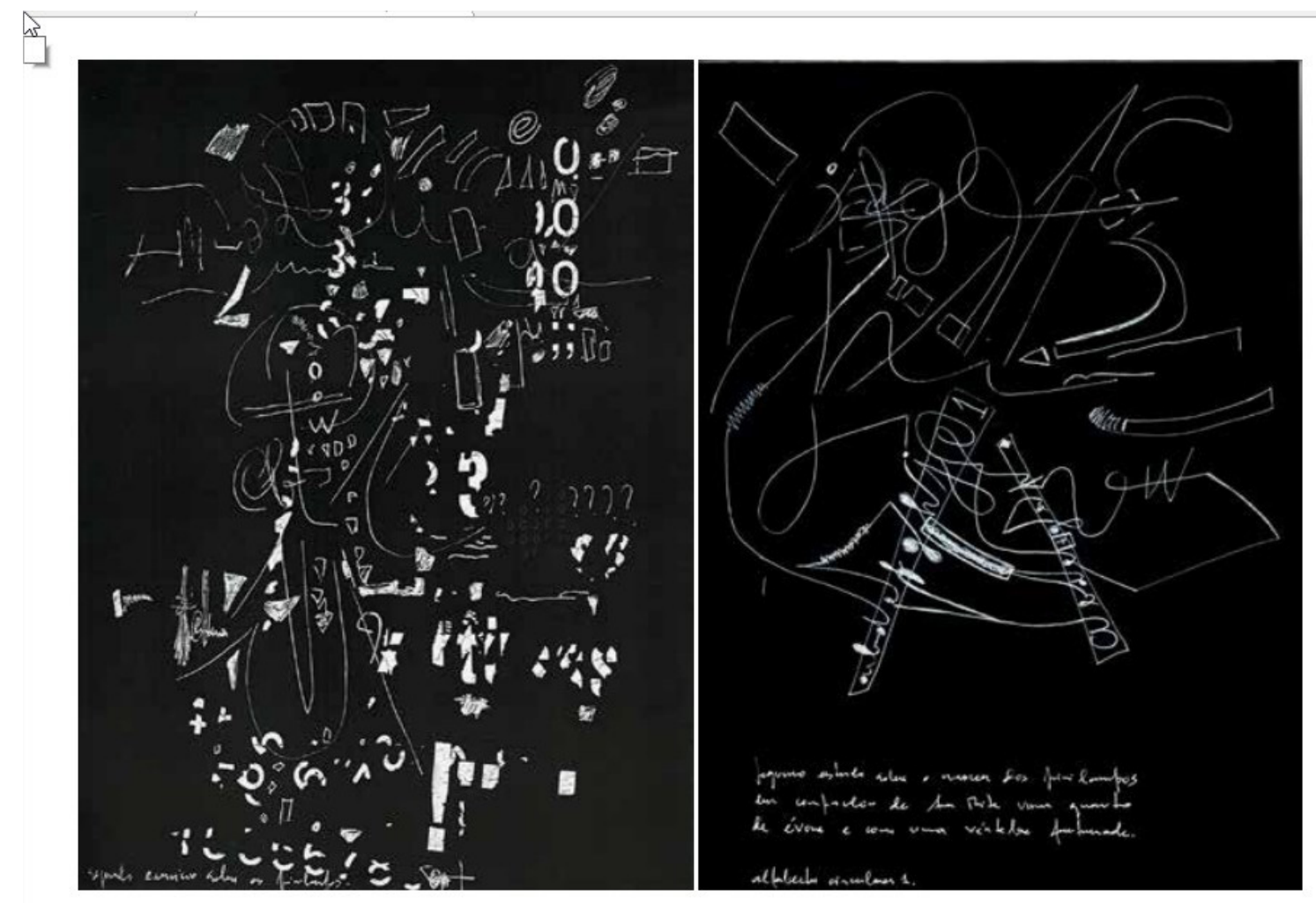

Fonte: MIRA, Feliciano, 2017. 
Em seguida, na página 106, aparentemente há uma virada temática. Temos uma imagem fotográfica modificada artisticamente que alude ao "habitar", à "geografia humana" e aos "sentidos do lugar", na cidade de "S. Paulo - onde está a cidade? (2015)". Se buscarmos uma sequência temos um contraste radical de experiência de vida, visto que no primeiro momento, no aeroporto - lugar de passagem, heterotopia -, há um encontro, em oposição à cidade de São Paulo da imagem, cuja estrutura hiperbólica da imagem transformada sugere fortemente, desencontros. Na sequência possível de interpretação do capítulo discutido, a menina no aeroporto alude ao familiar, ao encontro e reencontro, ao contato com o outro, as leituras de olhar, em oposição à ideia intrínseca da imagem da página 106. Se a pergunta pela cidade diz respeito ao que ela significaria como "lugar de reunião" e "lugar de acolhida", e em seu sentido mais estrito, "possibilidade de agregação", temos um asteísmo (longe de ser humor sardônico) acerca da estrutura urbana de uma capital superpopulosa que por si sua hipercoletividade dificultaria a observação deste sinal da infância aludido pela temática da "A Menina" (MIRA, 2017, p. 98-106).

"Rosa dos Ventos" inicia-se com os versos "alinha a bainha que desliza/ badala meia-noite ao Castelo de Arraiolos/ cosiam agulha e dedal pontos que o desejo lavrou/ e a lua cheia das papoilas beija de claridade a vila mais próxima da noite". Temos, nestes e nos versos seguintes, pequenas epifanias sobre o cotidiano. São cinco pequenas narrativas, ou microcontos, denominados, "Contra o esquecimento"; "e... de repente... o exílio"; "Não te perturbam os gritos?"; "Salmos do coração"; "sempre noiva e as romãs". Intrigante é a memória do lugar deste autor viajante e citadino, que não dissocia a natureza, a paisagem, as pessoas e os acontecimentos (o como elementos constituintes determinantes do sentido) dos lugares aos quais visita, a exemplo do verso: "tu dormias, eu ouvia a chuva em Willsden Green e os pássaros cinzelavam delírios nos olhos da chuva em Portobello Road".

A imagem mista e composicional de "Picotado de Buzeguim" (Londres, 1979) (MIRA, 2017, p.112) configura-se "metarte", em que o artista na lida e a obra produzida se interconectam como uma obra só, como num ciclo, uma alusão à obra em sua completude: da experiência do artista como meio (método) à realização da obra (fim...). Sobre a imagem de "Picotado de Buzeguim" (Londres, 1979) o artista é representado em seu trabalho, sobre o chão forrado por um grande pedaço de papel opaco. Estava ali a trabalhar a sua arte agregando elementos da pintura e da textura, em busca de uma forma que, esboçada ou não, em um dado momento apresentava-lhe a noção de obra concluída; a imagem ao lado desta fotografia é um desenho em preto e branco, e apresenta pontos cheios organizados em blocos (verticais, horizontais e perpendiculares); linhas paralelas estruturadas na horizontal parece desenhar uma perspectiva formal, que remete a uma paisagem abstrata, paisagem apenas como plano em altura, largura e profundidade; há especialmente duas setas que atravessam a imagem perpendicularmente; estas destoam da formalidade das outras linhas e pontos, de modo que pensamos numa intervenção cujo sentido maior é informar um movimento, um tráfego, um fim. Há dois pequenos monólito negros - um erguido e outro caído, fazendo ambos alusão ao tempo, no sentido duplo de permanência e efeméride. Fazem-nos lembrar dos elementos que compõem um mapa visual de uma cidade ou grande bairro visto de cima. Isto é prova do bastante complexo imaginário do autor, bem como dos seus recursos visuais, linguísticos e comunicacionais - além das modalidades de arte envolvidas (fotografia e desenhos). Nesta composição dialogam de forma poética (trânsito metafórico) a realidade do fazer artístico e a obra de arte concluída, num vínculo que atravessa o tempo do artista (enquanto produz) e o tempo (perene) da obra, apresentados no âmbito da inseparabilidade: 

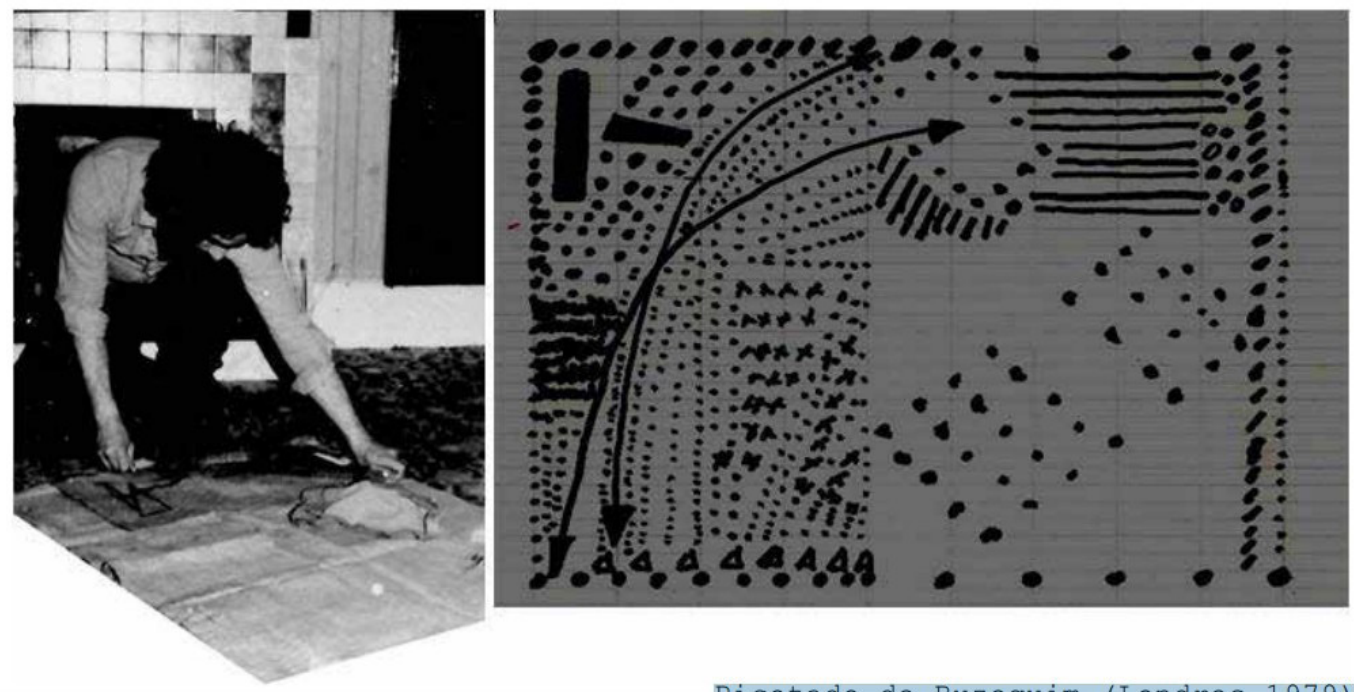

Fonte: MIRA, Feliciano, 2017.

Em "Cartografias do futuro passado" e "Cartografias do passado futuro" (MIRA, 2017, pp. 116117) o artista utiliza-se da escultura, da fotografia e do desenho (poesia visual) para compor sua obra. $O$ destaque é a forma como Mira utiliza o espaço vazio - na escultura com arame de clips -, que "vaza" em sua maior substância dentro do "sítio", isto é, das formas estruturais em linhas que circundam este vazio. Aí é possível entender que o vazio — que é delimitado nas formas estruturais — é um elemento importante sua composição. Na composição bipartida (abaixo, escultura; acima, desenho, das páginas 118/119) a complexidade do desenho nos faz pensar a escultura numa perspectiva menor e de recorte, mas a essência dos elementos de arte aí envolvidos possibilita um trânsito metafórico, no espaço um do outro, de modo que nos insinua a pensar a "forma" como elemento de destaque na composição, e não é a toa que recebe o título de "cartografias". Abaixo temos um exemplo em "Cartografias do futuro passado":
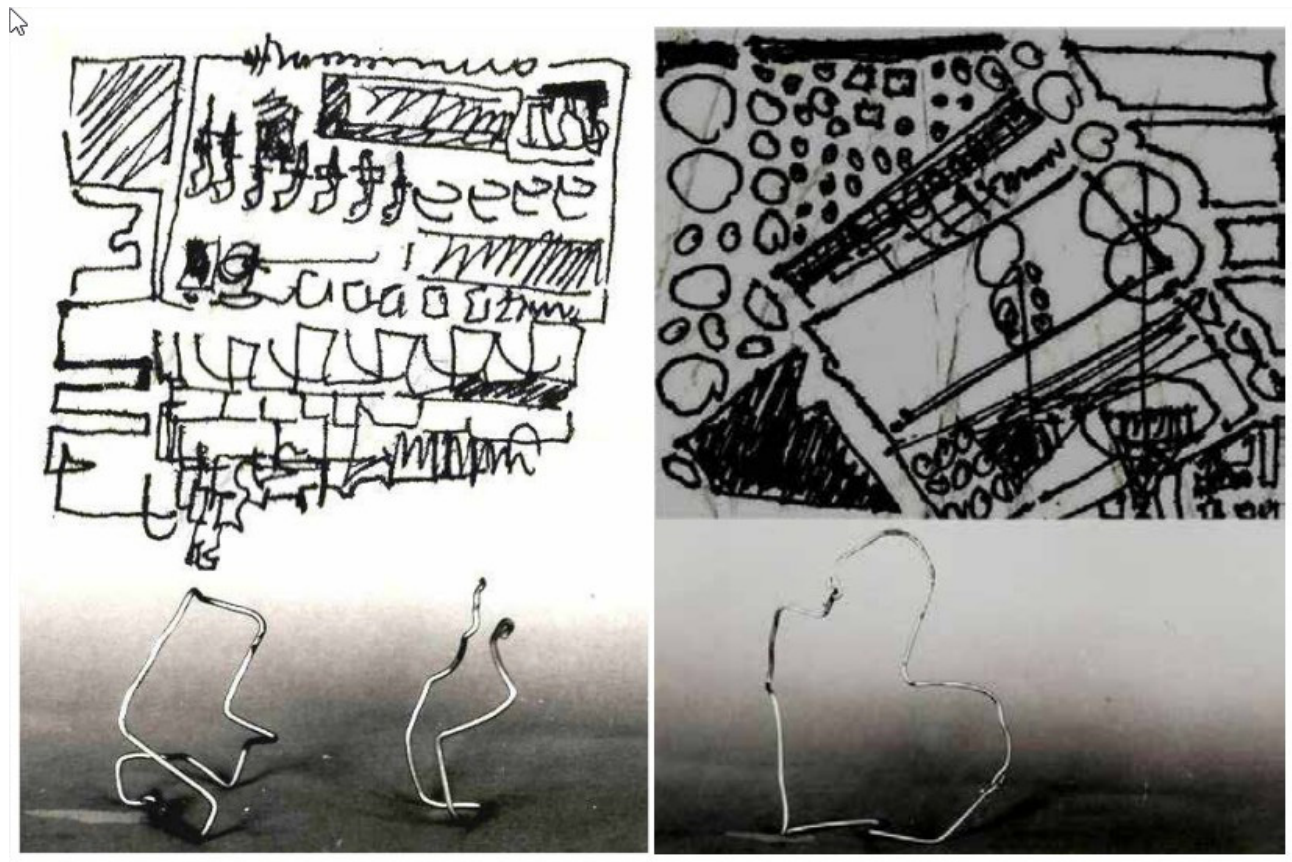

Fonte: MIRA, Feliciano, 2017. 
Em toda a sua narrativa, sobretudo acerca da Natureza que cerca, o homem é este último que imagina exercer algum controle sobre seu destino, visto que "são os homens do campo que vieram à vila acordar o que estava a dormir.”.

\section{Conclusões: a concretude do que se vê}

Em Mira (2016), a poética concreta e experimental inscreve-se pelo olho tipográfico e pictórico, e faz unir-se a dimensão de sentidos das palavras à forma e ao movimento figurativo do objeto representado; traduz e integra para o olhar o que vem a ser um pensamento imaginativo e projetivo: imaginativo porque essa poética é não-acabada, e projetivo pela imensa disposição à referenciação no âmbito das representações, por vezes integradas por similitude, ora por contrastes, com objetivo a engendrar a presença do que outrora era conceito, em suma, aquilo que o olhar apenas apreendia como signo e não como signo-forma. A arte de Feliciano de Mira não é simples, muito embora possa evidenciar um método, que, por assim dizer, possui como fundamento a multidisciplinaridade como disposição do pensamento, caminho e execução da obra - um forte exemplo é o de Hotel Siesta, em que o autor transforma em metáfora alguns ou muitos elementos presentes nas sentenças, frases, parágrafos, ou utiliza-se destas em suas composições, linhas e traços, etc.; o próprio título parece evocar uma metáfora. Por causa disso, esboçamos o conceito de "trânsito metafórico" com o intuito de pensar esta complexa obra e lançar luz sobre a produção e o pensamento sui generis do autor. E é a partir da obra deste, sobretudo da sua gênese, em evolução conceitual e teórica, no livro Ao Correr do Olhar - Contributos para uma epistemologia metafórica (2013) que temos os primeiros andamentos daquilo que ele denominou de "Saber Metafórico", isto é, um conhecimento pós-moderno que não prescinde dos conceitos da modernidade e de sua precisão como representação de mundo, e ainda acrescenta-se os aspectos mais subjectivos do espírito humano, esta dimensão vista pelo olhar oblíquo, porque é mais que sentido e diz respeito a experiência da presença como epifania cotidiana de mundo - é, sobretudo, por meio desta metáfora que nasce nas cidades por onde passa, que o "não-dito" se desvela no horizonte da compreensão, e o "dito" se ornamenta de uma "razão orgânica", telúrica e ao mesmo tempo "celeste”, feérica, intersubjetiva, onírica, lúdica, em que o afetivo nas artes pode ser compartilhado devidamente sem prescindir de linguagem adequada, mas acrescentando a esta uma extensão possível para aquilo que denominamos "margem de sentidos", inerente à linguagem — a epistemologia metafórica de Feliciano de Mira nos oferece grande possibilidades de transitar por sobre e entre os interstícios das cidades visitadas e rememoradas. 


\section{Referências}

ANTÔNIO, Jorge L. Poesia eletrônica: Negociações com os processos digitais. $1^{\mathrm{a}}$ ed. Belo Horizonte - BH. Veredas e cenários. 2008.

DA SILVA, Wellington Amancio. Hans Ulrich Gumbrecht Reader of Martin Heidegger: conception of presence production. In. Revista Brasileira de Estudos da Presença, Porto Alegre, v. 7, n. 3, p. 505522, Sept./Dec. 2017.

DE CAMPOS, Augusto; DE CAMPOS, Haroldo; PIGNATARI, Décio. Teoria da poesia concreta: textos críticos e manifestos 1950-1960. Livraria Duas Cidades, 1975.

GUMBRECHT, Hans. Graciosidade e Estagnação - ensaios escolhidos. Ed. PUC- Rio, Rio de Janeiro, 2012.

DE CAMPOS, Augusto; DE CAMPOS, Haroldo; PIGNATARI, Décio. Production of Presence: What Meaning Cannot Convey. Stanford: Stanford University Press, 2004.

JOYCE, J. - "EPIFANIAS", In. Revista da Letra Freudiana. Rio de Janeiro, Relume-Dumará, ano XII, $\mathrm{n}^{\circ} 13,1993$. p. 113

MIRA, Feliciano de. Ao Correr do Olhar - Contributos para uma epistemologia metafórica. Edições Subjectivas, Oficina do Espírito, Arraiolos: Portugal, 2013.

MIRA, Feliciano de. Hotel Siesta. Arraiolos, Portugal: Oficina do Espírito, 2017. 124 p.

POUND, Ezra. ABC da literatura. Tradução de Augusto de Campos e José Paulo Paes. 11 ed. São Paulo: Cultrix, 2006.

WHITE, Hayden: Meta-história: A imaginação Histórica do Século XIX. Tradução de José Laurênio de Melo. São Paulo: Editora da Universidade de São Paulo, 1995.

ZUMTHOR, Paul. Performance, Recepção, Leitura. Tradução de Jerusa Pires Ferreira e Suely Fenerich. 2a ${ }^{\mathrm{a}}$. ed. São Paulo: Cosac Naify, 2007. 
